\title{
HEART SOUNDS AND PRESSURES IN ATRIAL SEPTAL DEFECT
}

\author{
BY \\ D. W. BARRITT, D. H. DAVIES, AND G. JACOB \\ From the Cardiac Department, Bristol Royal Hospital
}

Received April 13, 1964

The existence of a large communication between the atria allows detailed study of sounds and pressures in the four heart chambers and the pulmonary arteries. Only the aorta is inaccessible to the cardiac catheter. In uncomplicated atrial septal defect, moreover, pressures within the heart chambers are almost normal. There are no important pressure gradients across the valves. It seems likely, therefore, that valve movements in this condition will resemble fairly closely those of the normal heart.

Using a saline-filled catheter and external manometer, previous authors have related sounds recorded at the præcordium to intracardiac pressure curves (Leatham and Gray, 1956; Dimond and Benchimol, 1959; Eisenberg and Hultgren, 1959). Sounds have also been recorded within the heart using a microphone mounted at the tip of a catheter and related to the conventional pressure records (Liu and Jacono, 1958; Feruglio and Sreenivasan, 1959; Lewis et al., 1959).

In an earlier paper (Barritt and Davies, 1963), we have described the use of the Allard Laurens intracardiac manometer and referred to the extensive observations of Souliés team in congenital heart disease (Soulié et al., 1961). This paper reports an analysis of records obtained with the intracardiac manometer in 23 patients with uncomplicated ostium secundum atrial septal defect.

\section{METHOD}

Præcordial phonocardiograms were recorded in a quiet room. Subsequently, right heart catheterization was performed using the Allard Laurens (Telco) intracardiac manometer. The catheter was advanced to the pulmonary artery and a præcordial microphone was then applied to give a simultaneous præcordial record. Inevitably, the præcordial phonocardiogram was of poorer quality at the time of catheterization as a result of discomfort and apprehension on the part of the patient and the higher noise level in the catheter room.

\section{RESULTS}

Activation Time of Ventricles. Records were obtained from both ventricles in 16 patients, from the right ventricle only in 6 , and from the left only in 1 . There was little difficulty in timing the onset of pressure rise in the ventricle to 0.01 second (Fig. 1). Onset of pressure rise was related to the first deflection of the QRS complex of the electrocardiogram.

Activation of the left ventricle preceded that of the right. The Q-L.V. time ranged from 0.020.045 with a mean of $0.032 \mathrm{sec}$. (Table).

Onset of pressure rise in the right ventricle was clearly delayed in patients 22 and $23(0.075$ and $0.09 \mathrm{sec}$.). Complete right bundle-branch block with a QRS duration of 0.14 and $0.15 \mathrm{sec}$. was present in both. In the remaining 21 patients, the width of the QRS complex in lead V1 was 


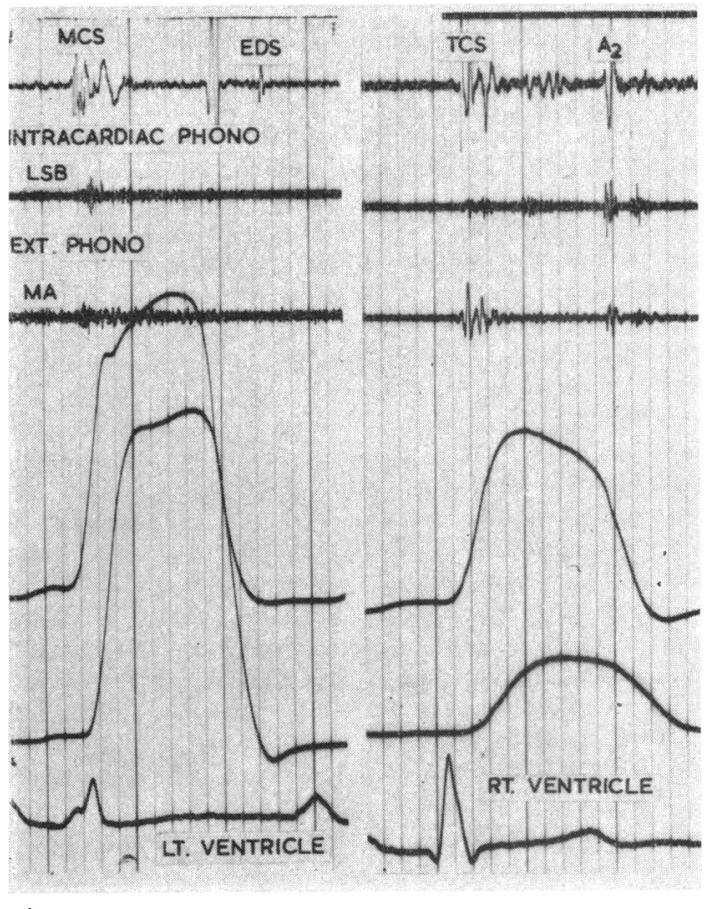

Fig. 1.-Recordings from above downwards: intracardiac phonocardiogram; external phonocardiogram, left sternal border; external phonocardiogram, mitral area; micromanometer pressure tracing; standard manometer pressure tracing; electrocardiogram, lead II, time scale $0.04 \mathrm{sec}$. $\mathrm{MCS}=$ mitral closing sound; EDS=early diastolic sound; TCS =tricuspid closing sound; $A 2=$ aortic second sound. In each ventricle the onset of pressure rise and first heart sound are related to the initial deflection of the electrocardiogram. A2 is recorded in both ventricles. P2 falls very low on the descending limb of the right ventricular pressure curve.

TABLE

Time Relationships of Sounds and Pressures in 23 Patients with Atrial Septal Defect

\begin{tabular}{|c|c|c|c|c|c|c|c|c|c|c|c|}
\hline \multirow{2}{*}{ Patient No. } & \multirow{2}{*}{$\begin{array}{c}\text { Q-S1 } \\
\text { first } \\
\text { element }\end{array}$} & \multirow{2}{*}{$\begin{array}{c}\text { Q-S1 } \\
\text { second } \\
\text { element }\end{array}$} & \multicolumn{2}{|c|}{ Q-pressure rise } & \multicolumn{2}{|c|}{ Q-S1 intracardiac } & \multirow{2}{*}{$\begin{array}{c}\text { Q-onset } \\
\text { pressure } \\
\text { rise in } \\
\text { P.A. }\end{array}$} & \multicolumn{2}{|c|}{ Pressures at P2 } & \multirow{2}{*}{ Q-A2 } & \multirow{2}{*}{$\begin{array}{c}\text { Q-onset } \\
y \text { descen } \\
\text { L.A. }\end{array}$} \\
\hline & & & R.V. & L.V. & $\begin{array}{l}\text { R.V. } \\
\text { (TCS) }\end{array}$ & $\begin{array}{l}\text { L.V. } \\
\text { (MCS) }\end{array}$ & & $\underset{(\mathrm{mm} . \dot{\mathrm{Hg}})}{\text { R.V. }}$ & $\begin{array}{l}\text { P.A. } \\
\text { (mm. } \mathbf{H g})\end{array}$ & & \\
\hline $\begin{array}{r}1 \\
2 \\
3 \\
4 \\
5 \\
6 \\
7 \\
8 \\
9 \\
10 \\
11 \\
12 \\
13 \\
14 \\
15 \\
16 \\
17 \\
18 \\
19 \\
20 \\
21\end{array}$ & $\begin{array}{l}0.05 \\
0.07 \\
0.07 \\
0.06 \\
0.05 \\
0.08 \\
0.08 \\
0.08 \\
0.06 \\
0.07 \\
0.07 \\
0.08 \\
0.07 \\
0.07 \\
0.065 \\
0.065 \\
0.07 \\
0.07 \\
0.06 \\
0.05 \\
0.06\end{array}$ & $\begin{array}{l}0.08 \\
0 \cdot 10 \\
0 \cdot 10 \\
0 \cdot 10 \\
0 \cdot 08 \\
= \\
\overline{-} \\
0 \cdot 09 \\
0 \cdot 10 \\
0 \cdot 11 \\
0 \cdot 11 \\
0 \cdot 13 \\
0 \cdot 13 \\
0 \cdot 115 \\
0 \cdot 12 \\
0 \cdot 10 \\
0 \cdot 095 \\
0 \cdot 12 \\
0.08 \\
0.08\end{array}$ & $\begin{array}{l}0.045 \\
0.045 \\
0.055 \\
0.04 \\
0.04 \\
0.05 \\
0.04 \\
0.045 \\
0.04 \\
0.03 \\
0.04 \\
0.04 \\
0.03 \\
0.05 \\
0.05 \\
0.045 \\
0.04 \\
0.035 \\
0.04 \\
0.04\end{array}$ & $\begin{array}{l}0.045 \\
0.025 \\
0.03 \\
0.03 \\
0.03 \\
0.03 \\
0.03 \\
- \\
\overline{0} \\
0.02 \\
0.04 \\
0.03 \\
0.035 \\
0.04 \\
0.04 \\
0.03 \\
0.03 \\
0.03 \\
-\end{array}$ & $\begin{array}{l}0.08 \\
0.09 \\
0.095 \\
0.08 \\
0.09 \\
0.08 \\
\overline{0.085} \\
0.07 \\
-\overline{0.065} \\
0.08 \\
0.08 \\
0.085 \\
0.08 \\
0.07 \\
0.07 \\
0.06 \\
0.075 \\
0.07\end{array}$ & $\begin{array}{l}\overline{-} \\
0.065 \\
0.08 \\
0.06 \\
0.065 \\
0.055 \\
0.05 \\
\overline{-} \\
0.05 \\
\overline{-} \\
\overline{-} \\
\overline{-} \\
0.05 \\
0.075 \\
0.06 \\
0.06 \\
0.065 \\
-\end{array}$ & $\begin{array}{l}0.07 \\
0.08 \\
0.09 \\
0.07 \\
0.09 \\
0.095 \\
0.06 \\
0.095 \\
= \\
\overline{-} \\
0.09 \\
0.09 \\
0.12 \\
0.08 \\
0.09 \\
0.085 \\
0.10 \\
0.08 \\
0.07\end{array}$ & $\begin{array}{r} \\
0 \\
3 \\
3 \\
-2 \\
-2 \\
-1 \\
4 \\
6 \\
3 \\
0 \\
9 \\
4 \\
0 \\
6 \\
6 \\
\\
3 \\
3\end{array}$ & $\begin{array}{r}12 \\
8 \\
11 \\
6 \\
9 \\
9 \\
12 \\
- \\
\overline{9} \\
10 \\
15 \\
10 \\
14 \\
11 \\
10 \\
12 \\
11\end{array}$ & $\begin{array}{l}0 \cdot 42 \\
0 \cdot 36 \\
0 \cdot 37 \\
0 \cdot 36 \\
\overline{0} \cdot 31 \\
\overline{-} \\
0 \cdot 36 \\
\overline{-} \\
0 \cdot 36 \\
0 \cdot 40 \\
0 \cdot 405 \\
0 \cdot 35 \\
0 \cdot 41 \\
0 \cdot 35 \\
0 \cdot 39 \\
0 \cdot 39 \\
-\end{array}$ & $\begin{array}{l}0.46 \\
0.38 \\
0.42 \\
0.41 \\
0.405 \\
0.36 \\
\overline{-} \\
0.405 \\
0.42 \\
0.48 \\
0.46 \\
0.40 \\
0.44 \\
0.405 \\
0.44 \\
0.44 \\
-\end{array}$ \\
\hline Mean values & 0.067 & $0 \cdot 103$ & 0.042 & 0.321 & 0.080 & 0.062 & 0.085 & $+2 \cdot 64$ & $10 \cdot 5$ & $0 \cdot 375$ & 0.426 \\
\hline $\begin{array}{l}22 \\
23\end{array}$ & $\begin{array}{l}0.11 \\
0.045\end{array}$ & $\overline{0.09}$ & $\begin{array}{l}0.08 \\
0.09\end{array}$ & $\underline{0.04}$ & $\begin{array}{l}0 \cdot 13 \\
0 \cdot 10\end{array}$ & $\underline{0.085}$ & $\overline{0.125}$ & $\begin{array}{l}-3 \\
-1\end{array}$ & $\begin{array}{l}4 \\
8\end{array}$ & 0.405 & 0.46 \\
\hline
\end{tabular}

TCS $=$ tricuspid closing sound.

MCS $=$ mitral closing sound. 


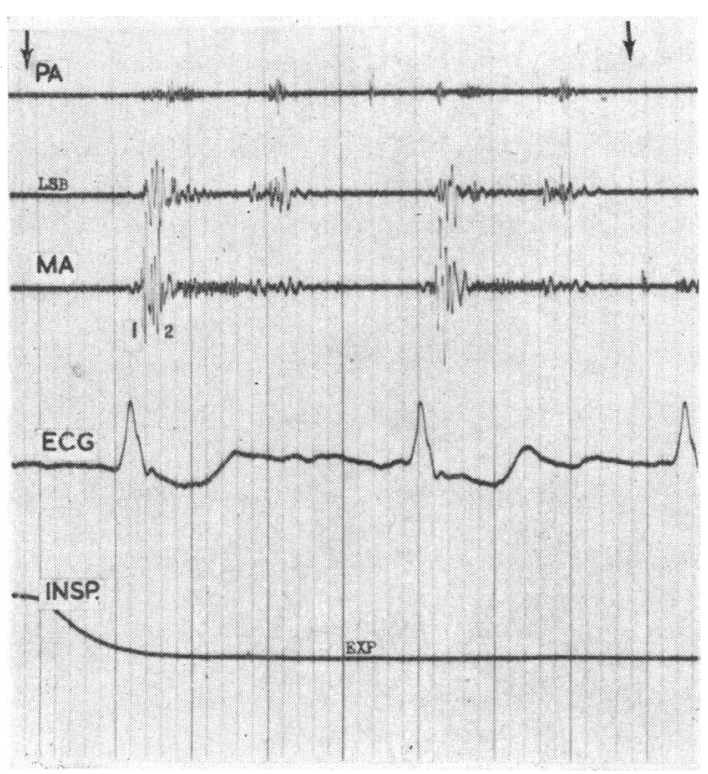

FIG. 2.-Recordings from above downwards: external phonocardiogram, pulmonary area; external phonocardiogram, left sternal border; external phonocardiogram, mitral area; electrocardiogram, lead II ; respiration. Note the two elements of the first heart sound.

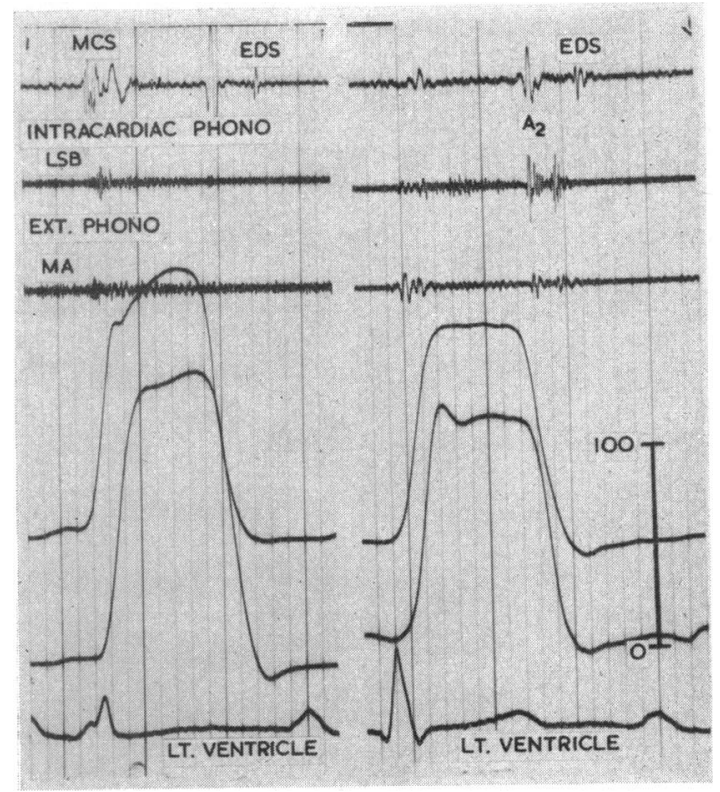

Fig. 4.-Left ventricular records. The upper pressure tracings are recorded by the micromanometer and the lower ones by the standard manometer. The left and right halves are from different patients. A2 falls on the descending limb of the pressure tracing. The interval from A2 to early diastolic sound is $0 \cdot 12 \mathrm{sec}$.

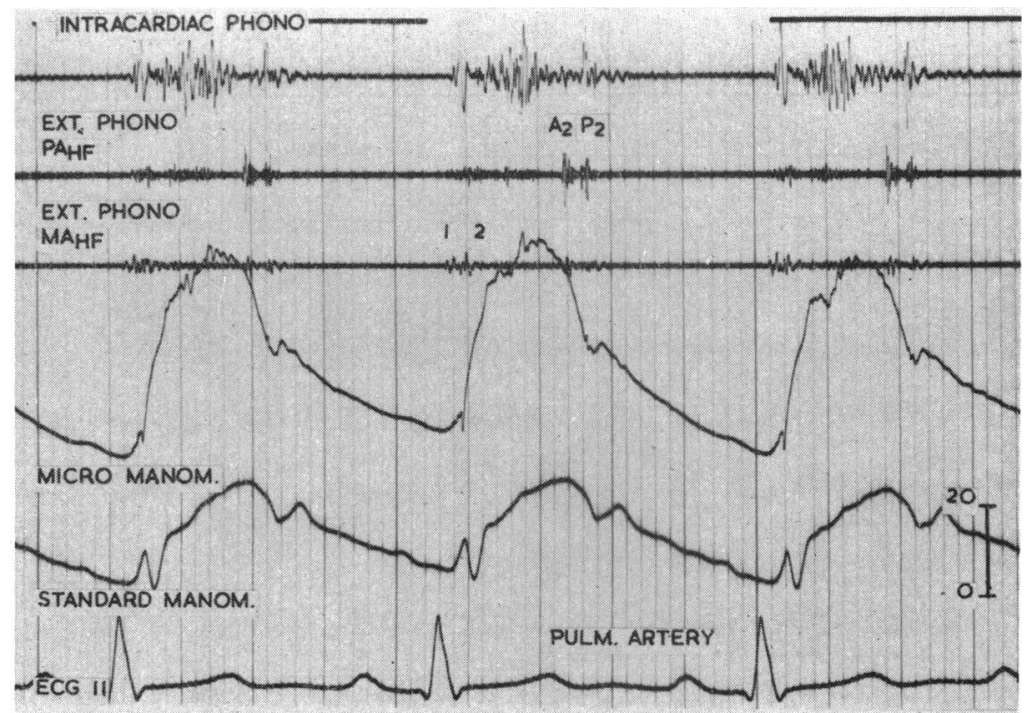

FIG. 3.-Onset of pressure rise in the pulmonary artery just precedes the second element of the first sound which is recorded at the mitral area, and which coincides with the first sound in the pulmonary artery. A2 precedes the dicrotic notch. P2 is synchronous. 
$0.12 \mathrm{sec}$. or less. In these, the Q-R.V. times ranged from $0.03-0.055 \mathrm{sec}$. with a mean of $0.042 \mathrm{sec}$. There was no tendency for the Q-R.V. time to be related to the width of the QRS.

The First Heart Sound. Splitting of the first heart sound in atrial septal defect is usually inconspicuous on auscultation, but two distinct elements of the first sound are often found in præcordial records (Leatham and Gray, 1956; Dimond and Benchimol, 1959; Eisenberg and Hultgren, 1959). Our præcordial phonocardiograms show two distinct elements of the first sound in 20 of the 23 cases (Fig. 2). Time values of the two elements from the onset of the QRS deflection are given in the Table. The mean interval between the two elements (excluding 2 patients with right bundle-branch block) is $0.036 \mathrm{sec}$.

Intracardiac sound records in either ventricle were analysed and two elements of the first sound were often found. The first element in each ventricle followed the rise in pressure in the ventricle and has been interpreted as representing mitral valve closure (MCS) in the left ventricle, and tricuspid valve closure (TCS) in the right. The Table shows the relationship of atrio-ventricular valve closure sounds to the electrocardiogram and to the rise in pressure in the ventricles. In both sides of the heart there is a measurable time delay between the onset of pressure rise in the ventricle and the beginning of the first sound; in the left ventricle a mean interval of $0.03 \mathrm{sec}$., and in the right of $0.035 \mathrm{sec}$. Analysis of the records of 10 patients in whom atrio-ventricular valve closure sounds were recorded clearly in both ventricles shows that in 2 the timing of both sounds was the same; in 8 mitral closure preceded tricuspid closure by intervals up to $0.025 \mathrm{sec}$. In the one patient with complete right bundle-branch block with first sounds recorded in both ventricles the interval was $0.04 \mathrm{sec}$.

It seemed clear that the two elements of the first sound recorded at the chest wall were considerably more widely separated than the mitral and tricuspid closure sounds. A later element of the first sound was, therefore, sought in records from both ventricles and from the pulmonary artery. Such sounds were found in 8 of 15 tracings from the left ventricle, 15 of 20 from the right ventricle, and 13 of 18 from the main pulmonary artery. The intracardiac phonocardiogram, therefore, failed to localize the site of origin of this late component of the first sound.

No record was obtained from the aorta in any case and the event which most closely coincided with the second element of the first sound was the onset of pressure rise in the pulmonary artery. Pressure rise in the pulmonary artery usually just preceded the second element of the first sound (Fig. 3). The average interval between the two in those cases where both events were recorded was $0.018 \mathrm{sec}$.

The Second Heart Sound. Præcordial records clearly showed two elements of the second heart sound in every case but one. Within the heart a loud sound was recorded in the left ventricle coinciding with the first element of the second sound. It marked the pressure tracing one-third of the way down the descending limb (Fig. 4). Pulmonary artery pressure tracings showed that this first part of the second sound always preceded the dicrotic notch of the pulmonary artery pressure tracing (Fig. 3). For these reasons, we have assumed this sound to be caused by aortic valve closure.

A sound coinciding with the second part of the second heart sound was recorded in the main pulmonary artery in every case in which the pulmonary artery was entered. The sound occurred at the same time as the dicrotic notch of the pulmonary artery pressure curve (Fig. 3). We have assumed this sound to be caused by pulmonary valve closure.

In the right ventricle it was a surprise to find sounds coinciding with aortic valve closure in 14 , whereas pulmonary closure sounds were found in only 4 . In these 4 , the sound in the right ventricle coincided exactly with the second element of the second sound at the præcordium (Fig. 1). Thus, by making use of the præcordial record the pulmonary closure sound could be related to the right ventricular curve in every case. A feature of the records has been that this sound is not registered until right ventricular pressure has fallen almost to zero (Fig. 1). As all the patients had normal pulmonary artery pressures, the highest diastolic pressure recorded in the pulmonary artery was $7 \mathrm{~mm}$. Hg. Measurements were made from successive tracings to compare pulmonary artery and right ventricular pressure at the time of pulmonary valve closure (Table). In every case but one, the 


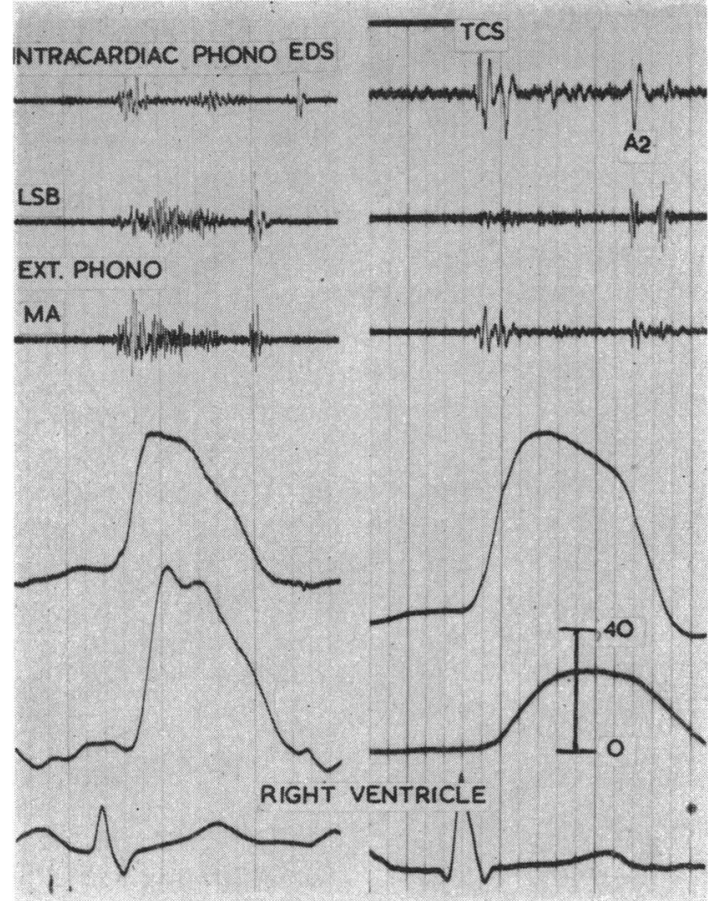

FIG. 5.-Right ventricular records, set out as in Fig. 4. Tricuspid closure sound follows the onset of pressure rise. The interval A2 to early diastolic sound is $0 \cdot 10 \mathrm{sec}$.

the manometer was withdrawn below the pulmonary valve (Fig. 6). The most intense systolic murmurs were associated with pressure gradients across the valve. The highest gradient was $45 \mathrm{~mm}$. Hg.

pulmonary artery pressure was higher than right ventricular pressure at the time of valve closure, the gradients ranging from -1 to 12 with a mean of $8 \mathrm{~mm}$. Hg.

Diastolic Sounds and their Relation to Atrial Pressures. Sharp sounds were recorded in the early part of diastole in both ventricles (Fig. 4 and 5). In the right ventricle such a sound was present in 10 of 22 records, and in the left ventricle in 6 out of 15 . In none was such a sound recorded in both ventricles. The sounds tended to be of greater intensity in the left ventricle. Præcordial phonocardiograms did not show any deflection coinciding with these early diastolic sounds.

Atrial pressure changes were studied and the onset of fall in pressure from the crest of the $V$ wave (onset of $y$ descent) was related to the aortic closure sound (Table). The time interval from aortic valve closure to the onset of the $y$ descent was usually $0.05 \mathrm{sec}$. In both atria the tracing of $y$ descent was similar.

Systolic Murmurs. A systolic murmur was recorded in the main pulmonary artery in every case. The murmur was well conducted into the branches of the pulmonary artery but was loudest just above the pulmonary valve. In every case the murmur ceased abruptly as the
monary valve (Fig. 6). The most intense systolic across the valve. The highest gradient was

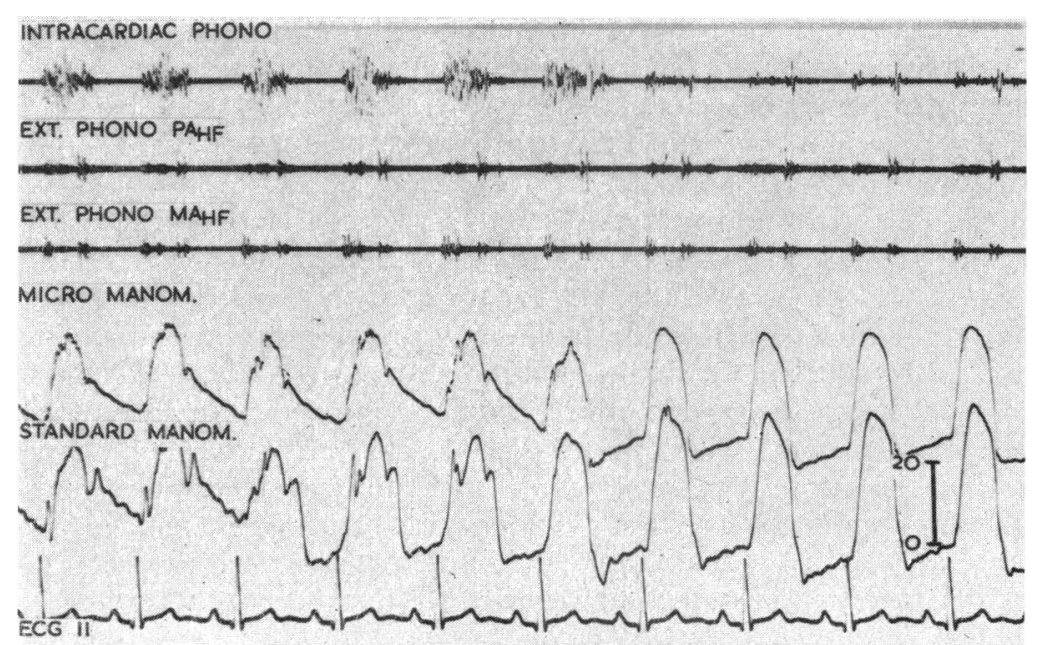

FIG. 6.-Recordings made during withdrawal from pulmonary artery to right ventricle. The systolic murmur of the intracardiac record ceases below the pulmonary valve. 


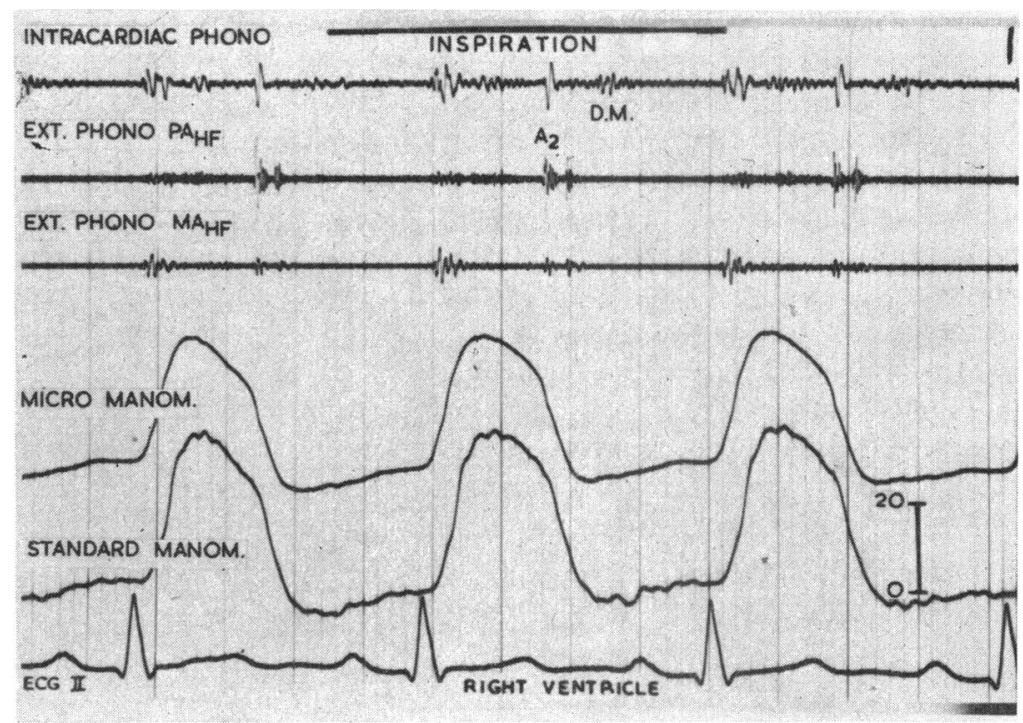

FIG. 7.-Recordings made in the inflow tract of the right ventricle. Note accentuation of diastolic murmur during inspiration.

Diastolic Murmurs. Præcordial phonocardiograms showed a delayed diastolic murmur clearly in 7, and less well in 3 further patients. Inspiration accentuated the murmur. Only one record was made, with the patient at rest. Similar murmurs were sought in intracardiac records particularly in the inflow tract of the right ventricle. A delayed diastolic murmur was recorded in 6 patients in the right ventricle and a presystolic murmur in 3 others. Inspiration increased the intensity of the earlier murmur (Fig. 7). A delayed diastolic murmur was also recorded in the right atrium in 3 patients and in the left atrium in 5.

\section{Discussion}

Activation of the Ventricle. Use of the intracardiac manometer with no transmission delay has allowed accurate timing of the onset of isovolumetric contraction of the ventricles. The left ventricle was activated first, as in normal hearts (Braunwald, Fishman, and Cournand, 1956; Di Bartolo et al., 1961). There was no important delay in activation of the right ventricle except in the two patients with complete right bundle-branch block. Leatham and Gray (1956) also found that delayed activation of the right ventricle was confined to patients with complete right bundle-branch block. Soulié et al. (1961) also found no significant delay in pressure rise in the right ventricle in atrial septal defect. It can be assumed that delayed activation of the right ventricle plays no part in producing the widely split second sound of atrial septal defect.

Time Pressure Relationships of Atrio-ventricular Valve Closure. The Table shows that there is always a delay between the onset of pressure rise in each ventricle and the registration of the first heart sound. Soulié et al. (1961) also noted a delay. There seems little doubt, therefore, that at the time of the first heart sound a pressure gradient exists between the ventricle and the atrium. Di Bartolo and co-workers (1961) measured this pressure gradient in dogs and found it to be $4 \mathrm{~mm}$. $\mathrm{Hg}$ in the right ventricle and $12 \mathrm{~mm} . \mathrm{Hg}$ in the left. Ventriculo-atrial pressure crossings preceded the first sound in either ventricle by $0.03 \mathrm{sec}$., almost exactly the same interval as in our patients.

Splitting of the First Heart Sound. Splitting of the first heart sound in these patients may be compared with a similar degree of splitting in normal subjects. Reinhold and Rudhe (1957) found that phonocardiograms of healthy adults showed two elements of the first sound which were separated 
by an average interval of $0.03 \mathrm{sec}$. Using an electrokymogram, they concluded that the second element preceded ejection into the pulmonary artery and was, therefore, likely to represent tricuspid valve closure. Splitting of the first sound in atrial septal defect was also noted by Leatham and Gray (1956), Dimond and Benchimol (1959), and Eisenberg and Hultgren (1959). These authors also considered that the late second element was likely to be due to delayed tricuspid valve closure.

Our records in the right ventricle appear to deny this possibility, for the average interval between the first heart sound in either ventricle was $0.015 \mathrm{sec}$., whereas the interval between the two sounds on the phonocardiogram was $0.037 \mathrm{sec}$. Furthermore, the pressure records leave no doubt that pulmonary artery pressure has begun to rise before the second element of the sound occurs. This clearly raises the possibility that the second element has origin in the great vessels and could well be an opening sound of the pulmonary valve Early systolic sounds immediately following the rise in pressure in the pulmonary artery were recorded in the main pulmonary artery in 13 of 18 patients (Fig. 3). However, similar sounds were also recorded in both ventricles in more than half of the cases. Moreover, we have no records from the region of the aortic valve. The proximity of the pulmonary artery to the chest wall and the accentuation and delay of the second element in patients with pulmonary hypertension or pulmonary stenosis supports the idea that this sound is produced as the pulmonary valve opens.

Splitting of Second Heart Sound. It has been generally assumed that the two elements of the second sound represent closure of the aortic and then the pulmonary valve. Soulié and his colleagues (1961) have been reluctant to accept this explanation. They point out that the second sound recorded in the right ventricle is synchronous with aortic valve closure. In addition, they consider that the position of this second sound in relation to the fall in pressure in the right ventricle indicates that the pulmonary valve closes at that moment. In our view, the second sound usually recorded in the right ventricle represents the aortic valve closure sound transmitted to the right ventricle. The loudness of the sound and the close proximity of the aortic valve to the right ventricle make this a reasonable assumption. This idea is strengthened by the fact that the aortic closure sound has also been found in records from the main pulmonary artery in 9 of 18 cases.

On the other hand, when the second element of the second sound, which we interpret as pulmonary valve closure, is related to the right ventricular pressure it has been a surprise to find that at the time the sound occurs, right ventricular pressure has fallen almost to zero. This would imply that at the time of pulmonary valve closure a pressure gradient exists between the pulmonary artery and the right ventricle. Measurements have shown that the average gradient is $8 \mathrm{~mm}$. $\mathrm{Hg}$. It has already been suggested with respect to atrio-ventricular valve closure that a pressure gradient exists between the ventricle and atrium at the time that valve closure sounds occur. It seems reasonable to postulate that a similar situation occurs at the time of pulmonary valve closure.

As to the cause of the delayed pulmonary closure sound, we have assumed that prolonged right ventricular systole is responsible. Measurements of the time intervals between the onset of pressure rise in the right ventricle and pulmonary valve closure confirm that the length of right ventricular systole is uninfluenced by respiration.

Early Diastolic Sounds. Early diastolic sounds were heard and recorded at the præcordium by Leatham and Gray (1956), who considered them to represent opening snaps of the tricuspid valve due to high flow. However, Dimond and Benchimol (1959) found only one such sound in 32 patients studied, and Eisenberg and Hultgren (1959) found none. In this study, records from either ventricle showed a sharp sound in early diastole in about half the cases. There was usually no corresponding sound in the præcordial records. Louder sounds were found in the left ventricle than in the right and we, therefore, have no evidence that tricuspid valve opening is unduly loud in atrial septal defect.

Study of consecutive tracings from ventricle and atrium showed that the $y$ descent of atrial pressure curves preceded the early diastolic sound in the ventricle by approximately $0.05 \mathrm{sec}$. Early diastolic sounds in the ventricles could be caused by atrio-ventricular valve opening (opening sound) or by rapid ventricular filling (third sound). The lateness of the sound with relation to the onset of 
fall in pressure in the atrium $(0.05 \mathrm{sec}$.) favours the idea that these are filling sounds rather than valve opening sounds.

It will be seen that the interval between aortic valve closure and the onset of $y$ descent in left atrial pressure $(0.05 \mathrm{sec}$.) is shorter than that between aortic closure and the opening sound of the mitral valve in conditions in which left atrial pressure is raised, such as mitral stenosis and incompetence and atrial myxoma (Nixon, 1961). This suggests again that the sound of valve movement does not occur until a measurable pressure gradient exists between the atrium and ventricle. The time interval between the pressure cross-over and the valve opening sound could well be 0.03 sec. Nixon (1961) commented on the time interval between the onset of $y$ descent and the mitral opening snap in mitral stenosis. He postulated that the early fall in left atrial pressure was due to active dilatation of the mitral ring. Our finding of a delay between the establishment of a pressure gradient from ventricle to atrium and the registration of the first heart sound as the valve closes suggests the likelihood of a similar delay as the valve opens.

Systolic Murmurs. Localization of the systolic murmur of atrial septal defect to the pulmonary valve confirms the view that high flow through the valve gives rise to an ejection murmur. In those cases with a pressure gradient the murmur is most intense. Pulmonary stenosis has been excluded in all 17 of the patients who have subsequently come to open-heart operation.

Delayed Diastolic Murmurs. Delayed diastolic murmurs were usually audible at the chest wall and were recorded in 10 of the 23 præcordial phonocardiograms. Increased blood flow through a normal tricuspid valve was considered to be the mechanism of production of this murmur by Leatham and Gray (1956), and by Liu and Jacono (1958). Using an intracardiac microphone, Liu and Jacono (1958) and Lewis et al. (1959) reached the same conclusion, though they recorded the murmur in the right ventricle in only 5 of 30 cases. Soulié et al. (1961) using the Telco intracardiac manometer were uncertain of the origin of the murmur. We have recorded a delayed diastolic murmur, which is accentuated in inspiration, in the inflow portion of the right ventricle in 6 of 22 patients. A somewhat similar murmur was found in the right atrium 3 times and the left 5 . In at least one patient there was also a similar murmur in the left ventricle; mitral stenosis was excluded. It still seems likely that the murmur is produced at the tricuspid valve at the time of rapid ventricular filling.

A criticism of our own records is that sufficient care was not always taken to make records very close to the tricuspid valve. Use of small intracardiac manometers shows repeatedly that sounds heard with ease at the chest wall may not be recorded if the manometer is moved only a centimetre or two from the site of origin. Thus, the murmur of rheumatic tricuspid stenosis, which is intense at the chest wall, may be recorded with ease at the valve orifice but is soon lost if the manometer is passed further into the ventricle.

\section{SUMMARY}

Præcordial phonocardiograms and the records obtained from the use of the Telco intracardiac manometer have been studied in 23 patients with uncomplicated ostium secundum atrial septal defect.

Records of sounds and pressures in both ventricles show that the split first sound is not due to delayed tricuspid valve closure. The second element of the first sound follows the rise in pressure in the pulmonary artery and may represent a pulmonary valve opening sound.

A measurable delay is found between the appearance of a pressure gradient between the ventricles and atria at the time of mitral and tricuspid valve closure and also between the pulmonary artery and right ventricle at the time of pulmonary valve closure. Left atrial pressure begins to fall 0.05 sec. after the aortic closure sound.

Ejection systolic murmurs were always localized to the pulmonary valve. Delayed diastolic murmurs were sometimes recorded in the inflow portion of the right ventricle.

We express our thanks to our chief technician, Mr. L. M. Clarke, for his great care in taking these records. H 


\section{REFERENCES}

Barritt, D. W., and Davies, D. H. (1963). Direct recording of sounds and pressures within the heart. Brit. Heart J., 25,549 .

Braunwald, E., Fishman, A. P., and Cournand, A. (1956). Time relationship of dynamic events in the cardiac chambers, pulmonary artery and aorta in man. Circulat. Res., 4, 100.

Di Bartolo, G., Nunez-Dey, D., Muiesan, G., MacCanon, D. M., and Luisada, A. A. (1961). Hemodynamic correlates of the first heart sound. Amer. J. Physiol., 201, 888.

Dimond, E. G., and Benchimol, A. (1959). Phonocardiography in atrial septal defect. Correlation between hemodynamics and phonocardiographic findings. Amer. Heart J., 58, 343.

Eisenberg, R., and Hultgren, H. N. (1959). Phonocardiographic features of atrial septal defect. Circulation, $20,490$.

Feruglio, A. G., and Sreenivasan, A. (1959). Intracardiac phonocardiogram in 30 cases of atrial septal defect. Circulation, 20, 1087.

Leatham, A., and Gray, I. (1956). Auscultatory and phonocardiographic signs of atrial septal defect. Brit. Heart J., 18, 193.

Lewis, D. H., Ertugrul, A., Deitz, G. W., Wallace, J. D., Brown, J. R., and Moghadam, A. (1959). Intracardiac phonocardiography in the diagnosis of congenital heart disease. Pediatrics, 23, 837.

Liu, C. K., and Jacono, A. (1958). Phonocardiography in atrial septal defect. Amer. J. Cardiol., $2,714$.

Nixon, P. G. F. (1961). Time relationships of the left atrial $\mathrm{V}$ wave in mitral valvular disease. Brit. Heart J., 23, 637.

Reinhold, J., and Rudhe, U. (1957). Relation of the first and second heart sounds to events in the cardiac cycle. Brit. Heart J., 19, 473.

Soulié, P., Baculard, P., Bouchard, F., Cornu, C., Laurens, P. and Wolff, F. (1961). Le cathéterisme du cœur au micromanomètre. Arch. Mal. Caur, Suppl. I. 